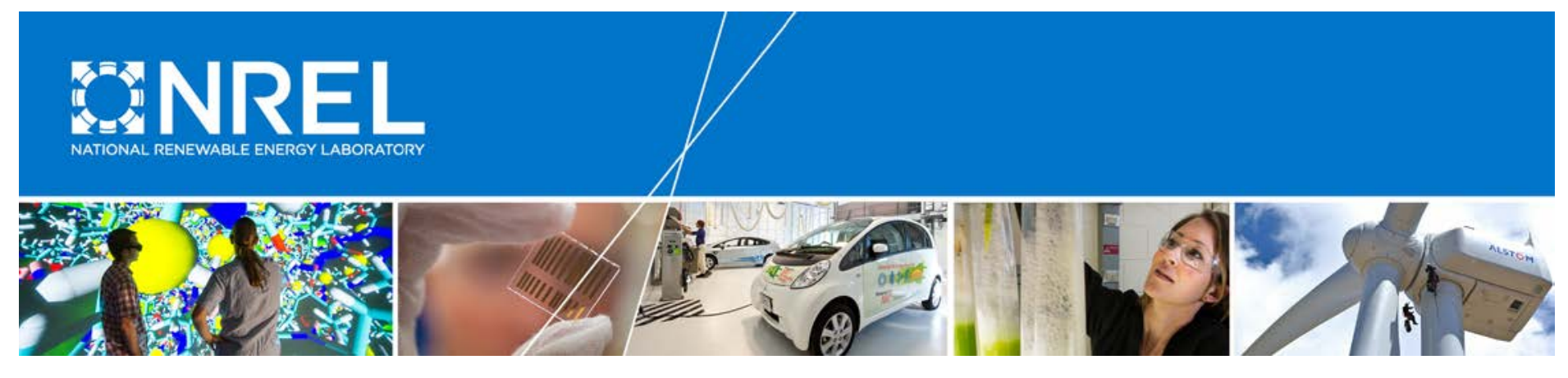

\title{
Lidar-Enhanced Wind Turbine Control: Past, Present, and Future
}

\section{Preprint}

Andrew Scholbrock, Paul Fleming, Alan Wright, and Na Wang

National Renewable Energy Laboratory

David Schlipf

Stuttgart Wind Energy

Kathryn Johnson

National Renewable Energy Laboratory and Colorado School of Mines

Presented at the 2016 American Control Conference Boston, Massachusetts

July 6-8, 2016

NREL is a national laboratory of the U.S. Department of Energy Office of Energy Efficiency \& Renewable Energy Operated by the Alliance for Sustainable Energy, LLC

This report is available at no cost from the National Renewable Energy Laboratory (NREL) at www.nrel.gov/publications.

Conference Paper

NREL/CP-5000-65879

July 2016

Contract No. DE-AC36-08GO28308 


\section{NOTICE}

The submitted manuscript has been offered by an employee of the Alliance for Sustainable Energy, LLC (Alliance), a contractor of the US Government under Contract No. DE-AC36-08GO28308. Accordingly, the US Government and Alliance retain a nonexclusive royalty-free license to publish or reproduce the published form of this contribution, or allow others to do so, for US Government purposes.

This report was prepared as an account of work sponsored by an agency of the United States government. Neither the United States government nor any agency thereof, nor any of their employees, makes any warranty, express or implied, or assumes any legal liability or responsibility for the accuracy, completeness, or usefulness of any information, apparatus, product, or process disclosed, or represents that its use would not infringe privately owned rights. Reference herein to any specific commercial product, process, or service by trade name, trademark, manufacturer, or otherwise does not necessarily constitute or imply its endorsement, recommendation, or favoring by the United States government or any agency thereof. The views and opinions of authors expressed herein do not necessarily state or reflect those of the United States government or any agency thereof.

This report is available at no cost from the National Renewable Energy Laboratory (NREL) at www.nrel.gov/publications.

Available electronically at SciTech Connect http:/www.osti.gov/scitech

Available for a processing fee to U.S. Department of Energy and its contractors, in paper, from:

U.S. Department of Energy

Office of Scientific and Technical Information

P.O. Box 62

Oak Ridge, TN 37831-0062

OSTI http://www.osti.gov

Phone: 865.576.8401

Fax: 865.576.5728

Email: reports@osti.gov

Available for sale to the public, in paper, from:

U.S. Department of Commerce

National Technical Information Service

5301 Shawnee Road

Alexandria, VA 22312

NTIS http://www.ntis.gov

Phone: 800.553 .6847 or 703.605 .6000

Fax: 703.605.6900

Email: orders@ntis.gov 


\title{
Lidar-Enhanced Wind Turbine Control: Past, Present, and Future
}

\author{
Andrew Scholbrock ${ }^{1}$, Paul Fleming ${ }^{1}$, David Schlipf ${ }^{2}$, Alan Wright ${ }^{1}$, Kathryn Johnson ${ }^{1},{ }^{3}$ and Na Wang ${ }^{1}$
}

\begin{abstract}
The main challenges in harvesting energy from the wind arise from the unknown incoming turbulent wind field. Balancing the competing interests of reduction in structural loads and increasing energy production is the goal of a wind turbine controller to reduce the cost of producing wind energy. Conventional wind turbines use feedback methods to optimize these goals, reacting to wind disturbances after they have already impacted the wind turbine. Lidar sensors offer a means to provide additional inputs to a wind turbine controller, enabling new techniques to improve control methods, allowing a controller to actuate a wind turbine in anticipation of an incoming wind disturbance.

This paper will look at the development of lidar-enhanced controls and how they have been used for various turbine load reductions with pitch actuation, as well as increased energy production with improved yaw control. Ongoing work will also be discussed to show that combining pitch and torque control using feedforward nonlinear model predictive control can lead to both reduced loads and increased energy production. Future work is also proposed on extending individual wind turbine controls to the wind plant level and determining how lidars can be used for control methods to further lower the cost of wind energy by minimizing wake impacts in a wind farm.
\end{abstract}

\section{INTRODUCTION}

Power generation from wind energy is complex, mainly due to the fact that the energy source for a wind turbine is largely unknown until the energy source impacts the turbine. This has inspired many research topics on controls for wind turbines, all with a similar goal: to minimize the levelized cost of energy (LCOE). This general goal can be broken into two major subgoals: increasing the energy production of a wind turbine, and reducing the loads experienced by a wind turbine to extend the turbine lifetime.

An example of using controls to reduce the loads experienced by a wind turbine is to control the pitch of the blades. Initial constant-pitch wind turbines experienced large aerodynamic loading on the blades when a wind gust would impact the turbine [1]. With the advent of variable-pitch blades and controls, wind turbines were able to pitch the blades to feather, reducing the aerodynamic loads experienced by the wind turbine [1]. This led to wind turbines being redesigned to produce the same or larger amount of energy with reduced materials in the wind turbine.

This example does not address the fact that the controller used a feedback design, meaning that the wind turbine is

\footnotetext{
${ }^{1}$ National Renewable Energy Laboratory 15013 Denver West Parkway Golden, CO 80401. NREL is a national laboratory of the U.S. Department of Energy, Office of Energy Efficiency and Renewable Energy, operated by the Alliance for Sustainable Energy LLC. andrew. scholbrockenrel.gov

${ }^{2}$ Stuttgart Wind Energy, Universität Stuttgart, Allmandring 5B, 70569 Stuttgart, Germany.

${ }^{3}$ Colorado School of Mines, 1500 Illinois St., Golden, CO 80401.
}

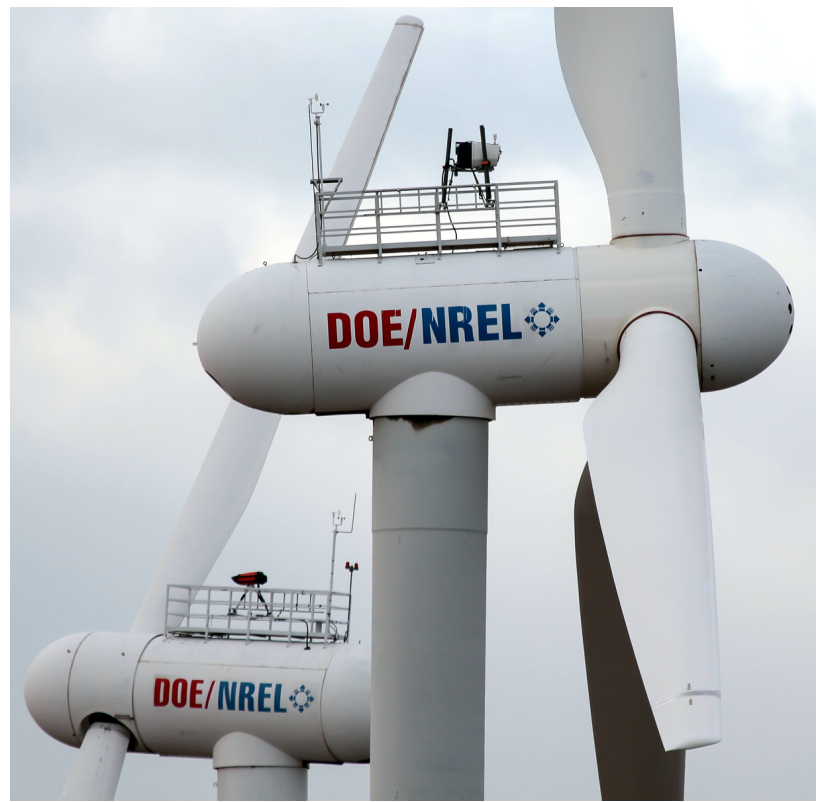

Fig. 1. Lidars mounted on two- and three-bladed research wind turbines at the National Wind Technology Center. (Photo by Lee Jay Fingersh, NREL 32910)

reacting to the wind disturbance that has already impacted the wind turbine. In essence, this is similar to driving a car while blindfolded and reacting to how the car feels. To address this, light detection and ranging (lidar) technology has been proposed as a new sensing capability to measure the wind before it impacts the turbine [2]. In the driving analogy, this allows the blindfold to be removed to see ahead and anticipate control inputs before reacting to a disturbance. An initial simulation study showed good promise that including lidars with wind turbines could lead to lowering the LCOE of wind turbines [2].

Other research has followed the example of [2] using lidars to enhance wind turbine controls. This has included field testing where lidars have been mounted on the nacelles of wind turbines as seen in Fig. 1. The goal of this paper is to survey the lidar-enhanced wind turbine controls research and draw conclusions based on this research.

\section{BACKGROUND INFORMATION}

\section{A. Wind Turbine Control Basics}

Most utility-scale wind turbines today are configured as upwind horizontal-axis machines and are capable of running at variable speeds through command of the torque of the generator. Further, most wind turbines also have the capability of varying the pitch angle of the blades. For large- 
scale turbines, the nacelle is actively controlled to change the turbine's yaw direction so that the turbine is aligned with the wind direction. These three actuation methods, torque, pitch and yaw, are three typical control actions of a wind turbine [3] and are discussed throughout this paper.

A typical utility-scale wind turbine operates in three regions: Region 1 - the turbine sits idle waiting for the wind speed to increase as there is not enough wind to operate the turbine, Region 2 - the turbine's rotor speed is varied to maximize the rotor efficiency with a fixed blade pitch, and Region 3 - the turbine's generator torque is fixed and the blade pitch is varied to control a fixed rotor speed. Figure 2 illustrates the different regions and how the power production varies from region to region. The red curve in Fig. 2 shows the power available in the wind as given by equation 1 :

$$
P_{\text {wind }}=\frac{1}{2} \rho A v^{3}
$$

where $P_{\text {wind }}$ is the power available in the wind, $\rho$ is the air density, $A$ is the rotor area, and $v$ is the wind speed. The blue curve in Fig. 2 accounts for the aerodynamic efficiency of the wind turbine, given by the ratio in equation 2 :

$$
C_{p}=\frac{P}{P_{\text {wind }}}
$$

where $C_{p}$ is the power coefficient, $P$ is the power captured by the wind turbine, and $P_{\text {wind }}$ is the power available in the wind. $C_{p}$ is governed by many factors, but two of interest are the blade pitch angle and the tip speed ratio, which relates the blades tip speed to the wind speed as seen in equation 3 :

$$
\lambda=\frac{\omega R}{v}
$$

where $\lambda$ is the tip speed ratio, $\omega$ is the rotor speed, $R$ is the rotor radius and $v$ is the wind speed.

Due to turbulence, the wind speed varies from one point in the rotor to another and therefor the wind speed is not typically used as a feedback signal to the controller. Instead, the generator speed is used as a feedback signal, and in Region 2, the commanded torque is determined from the generator speed using equation 4 :

$$
\tau=K \omega^{2}
$$

where $\tau$ is the generator torque, $\omega$ is the generator speed, and $K$ is a constant given by:

$$
K=\frac{1}{2} \rho \pi R^{5} \frac{C_{p_{\max }}}{\lambda_{*}^{3}}
$$

where $C_{P_{\max }}$ is the maximum power coefficient and $\lambda_{*}$ is the tip speed ratio at the maximum power coefficient. Thus, when the wind speed increases, the rotor (and generator) accelerates, and the commanded torque increases. This in turn decelerates the rotor, balancing the acceleration from the wind.

In Region 3, the commanded torque is held constant at the rated torque value. In this region, the blade pitch angle is varied to change the $C_{p}$ value of the turbine. Hence, if the wind speed increases, the rotor begins to accelerate, and the

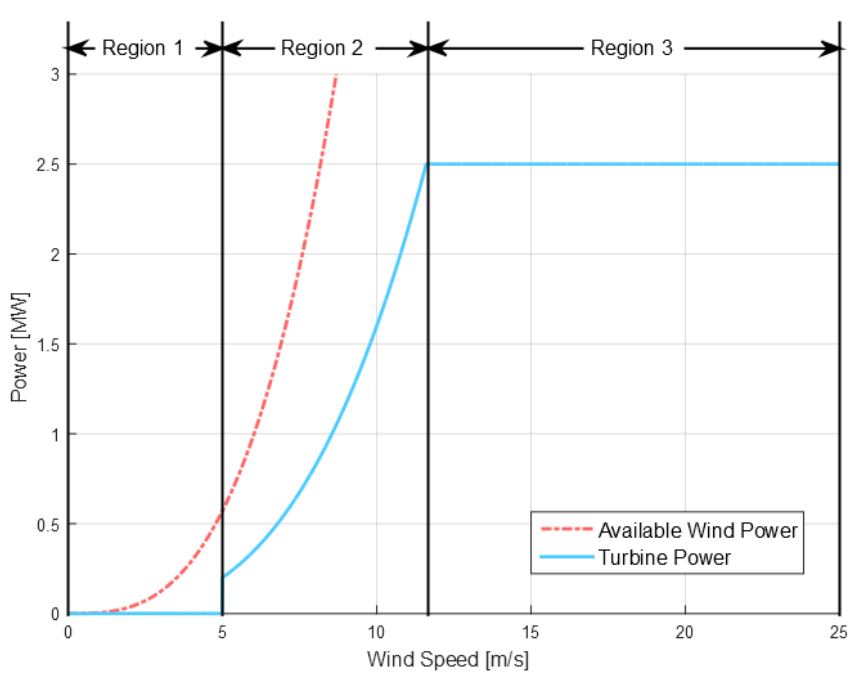

Fig. 2. Power curves for different wind speeds. The "Available Wind Power" red curve is the total power available at a given wind speed, and the "Turbine Power" blue curve is the power that a wind turbine is able to produce at a given wind speed. The different regions of operation are given at the top of the figure.

controller varies the blade pitch angle to lower the $C_{p}$ value, which in turn decelerates the rotor until a balance is found. For some controllers, there exists a transition region between Region 2 and Region 3, known as Region 2.5, where the rotor speed reaches its rated value before the generator torque reaches its rated value. Controllers use different techniques to ensure a smooth transition, such as a generator-slip control method. For more detail on wind turbine control, refer to [3].

In addition to torque and pitch control, a horizontalaxis wind turbine needs the rotor to be aligned with the wind direction to produce the maximum possible power. As mentioned earlier, this is done actively for large scale wind turbines, which traditionally rely on a nacelle-mounted wind vane to align it with the wind direction. Building off of equations 1 and 2 , the theoretical power captured by a wind turbine can be expressed by the following equations [4]:

$$
\begin{gathered}
P_{\text {max }}=\frac{1}{2} \rho A C_{P} V_{p}^{3} \\
V_{p}=V_{0} \cos \left(\theta_{E}\right)
\end{gathered}
$$

Equation 6 shows that the maximum power $\left(P_{\max }\right)$ that could be captured depends on the wind speed perpendicular to the rotor plane $\left(V_{p}\right)$. In equation 7 , the perpendicular component of the wind speed is expressed in terms of the freestream wind speed $\left(V_{0}\right)$, and the cosine of the yaw alignment error $\left(\theta_{E}\right)$ and is illustrated by the green vector component in Fig. 3. Combining these two equations implies that a yaw misalignment reduces the power produced by the wind turbine, hence it is the goal of a yaw controller to minimize the yaw misalignment.

\section{B. Lidar Basics}

To remotely measure the wind velocity, a lidar sends out a laser beam which reflects back to the lidar from particulates 
in the atmosphere. A comparison of the sent and reflected wavelength is then performed, and the Doppler effect is used to derive the wind speed [5]. To get a high quality measurement, there needs to be enough backscattered light from the atmosphere to have a high carrier-to-noise ratio. Different factors can impact the carrier-to-noise ratio of the lidar measurement, including the amount of particulates in the atmosphere, weather conditions, as well as the installed location on a wind turbine [6].

There are two types of lidars that use different methods to calculate a wind speed measurement. The first type of lidar is a continuous-wave lidar (illustrated in Fig. 4), which uses a laser beam that is focused at a desired distance ahead of the lidar, known as the focal distance. The second type of lidar is a pulsed lidar, which uses a timing-based method that waits for the reflected light to return at different times after a pulse of light is emitted from the lidar, thereby allowing it to measure the wind speed at different distances [7].

These two methods measure the wind speed along the lineof-sight (LOS) of the laser beam as illustrated in Fig. 3. To estimate a wind velocity, a lidar needs to take multiple measurements in different directions, which can be done either by scanning the wind field with a rotating beam (seen in continuous-wave lidar systems) or by switching the beam between different staring positions (seen in pulsed lidar systems). The angle between the lidar's center line and the LOS measurement is known as the half-cone angle as illustrated by $\phi$ in Fig. 3. Simulation studies have been done to determine the optimal settings of the focal distance, half-cone angle, and measurement frequency [7], [8]. Additionally, the correlation between the lidar measurements and the turbine's reaction can be analytically determined based on the spectral properties of the wind. This allows directly optimizing a lidar scan configuration, avoiding extensive simulation studies [9], [10]. These studies have shown that different settings are optimal for different control objectives. For example, a wider cone angle is more desirable when trying to measure wind direction, even though this diminishes the measurement quality of the wind speed [7]. Additionally, a lidar could be mounted in the hub of a wind turbine in such a way that the lidar measurement will be rotating with the rotor's speed, allowing for the lidar wind measurement to have a higher coherence with the wind experienced by each blade [10].

The scanning/staring methods use a single lidar system, and therefore the LOS measurements are taken at different locations and at different times. To resolve the LOS wind speed measurements into signals for control such as the rotor-effective wind speed, wind shears, and wind direction, some assumptions are needed and wind field reconstruction methods need to be applied [11], [12], [13]. Another method is to use several lidar systems in different ground-based locations that are controlled to measure the same atmospheric location [5].

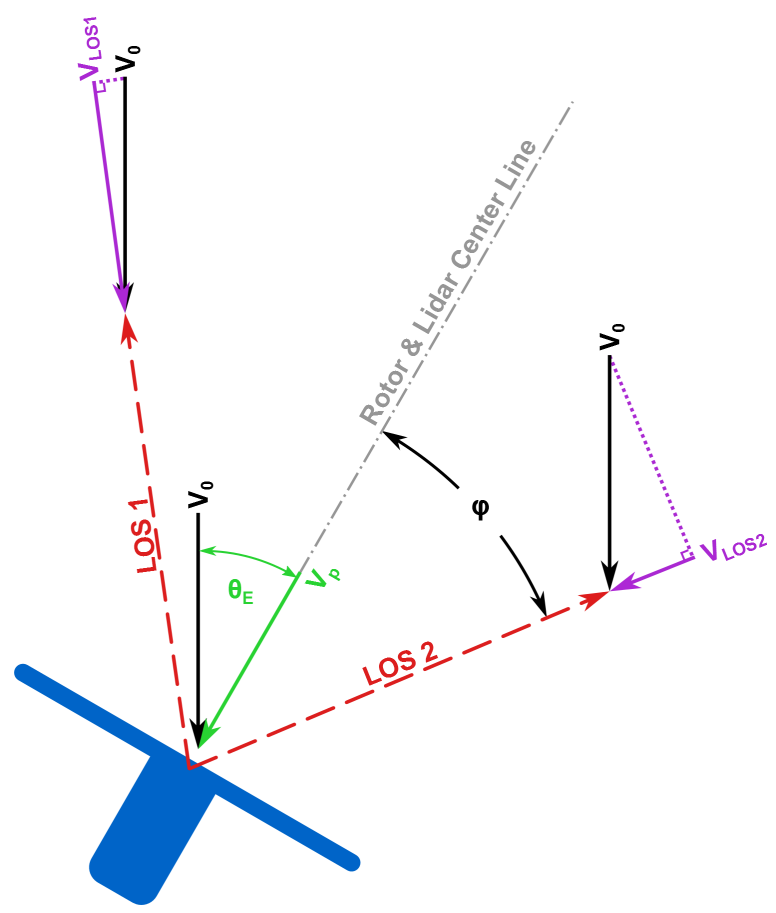

Fig. 3. An example of a nacelle-mounted lidar with two LOS beams shown in red and the corresponding LOS wind measurements shown in purple. The turbine in blue is shown with a yaw misalignment, $\theta_{E}$, and the wind component perpendicular to the rotor plane, $V_{p}$, is shown in green. The angle $\phi$ is the lidar's half cone angle. For simplicity, a uniform wind field is shown as black vectors, $V_{0}$.

\section{LITERATURE REVIEW}

\section{A. Online Lidar Data Processing}

Before the lidar measured data can be used for control in wind turbines, the lidar data must be processed to transform LOS wind speed measurements into signals that can be readily used by the turbine controller. Having a high coherence between the lidar measurement and what is processed to be the estimated rotor-effective wind speed is essential for feedforward control to be advantageous. In [14], it was shown that an increasing amount of coherence will lead to greater improvements from using feedforward control.

Because the lidar data are being measured ahead of the wind turbine, some delay needs to be taken into account for the measured wind to travel to the wind turbine. A simple way to resolve this is to use Taylor's frozen turbulence hypothesis [15], which states that the time $(t)$ it will take for the wind to reach the turbine is equal to the measured distance $(d)$ divided by the mean flow velocity $(\bar{V})$ as seen in equation 8 .

$$
t=\frac{d}{\bar{V}}
$$

In [16], it was found from field experiments that Taylor's frozen turbulence hypothesis was suitable for wind turbine control. Improvements can be made on the coherence between the lidar measurement of the wind speed and the rotor-effective wind speed by avoiding the Taylor hypothesis, by decoupling the time delay from the mean wind speed in 
equation 8 , which has been done in simulation [17], and additionally from analyzing field test data [18].

The turbulence of the wind must also be considered in that eddies measured by the lidar will evolve over time and not necessarily correlate to the wind that is experienced later by the wind turbine. Smaller eddies dissipate on short timescales, and trying to control them is unnecessary, whereas larger eddies are more coherent over longer timescales. Hence, it is necessary to filter the lidarmeasured wind speed so that lower-frequency measurements are controlled for, and higher-frequency measurements are filtered out [19]. Additional data processing using wind measurements taken from different distances can be used to improve the coherence between the lidar measurement and the rotor-effective wind speed [13].

Additional consideration of the current atmospheric conditions the wind turbine experiences could be taken into account when optimizing the lidar's processing parameters for wind turbine control applications. As conditions vary, the turbulence statistics will change and it will be desirable to change the settings of a lidar to optimize the measurement for these differences. In [20], simulation studies showed that a longitudinal spatial coherence model could be developed with varying atmospheric conditions. From the model developed, the work in [20] went on to evaluate the optimal scan radius and the optimal preview distance for a continuouswave lidar as a function of the turbulence intensity and mean wind speed. Results in [20] showed that the optimal scan radius increased for lower mean wind speeds, and the optimal preview distance increased for lower turbulence intensities.

\section{B. Pitch Control}

Feedforward lidar control differs from standard wind turbine feedback control in that control decisions are made in anticipation of future events, and with lidars this is based on a measurement of the wind field ahead of the wind turbine. As mentioned in Section III-A, after the lidar measurement is made, data processing is necessary to account for the wind evolution as it transports to the wind turbine. This process is illustrated in the red blocks in Fig. 5. An advantage of this design is that if a fault is detected in the feedforward process, it can simply be switched off, and the feedback only portion of the controller can take over the control of the wind turbine.

An initial study looked to combine a standard feedback controller with a feedforward blade pitch controller using lidar wind preview measurements [21] like the process shown in Fig. 5. The controller design allowed for a preview pitch angle to be determined from the lidar wind measurement, and known rotor aerodynamics using a nonlinear look-up table of the static pitch angle. Using a FAST simulation environment, results showed that with the preview control a decrease of $70 \%-80 \%$ in the standard deviation of the rotor speed was achievable without increasing the pitch rate activity. The work in [22] looked to further investigate the results from [21] by using a model-inverse technique: NonCausal Series Expansion (NCSE). Using this method with a

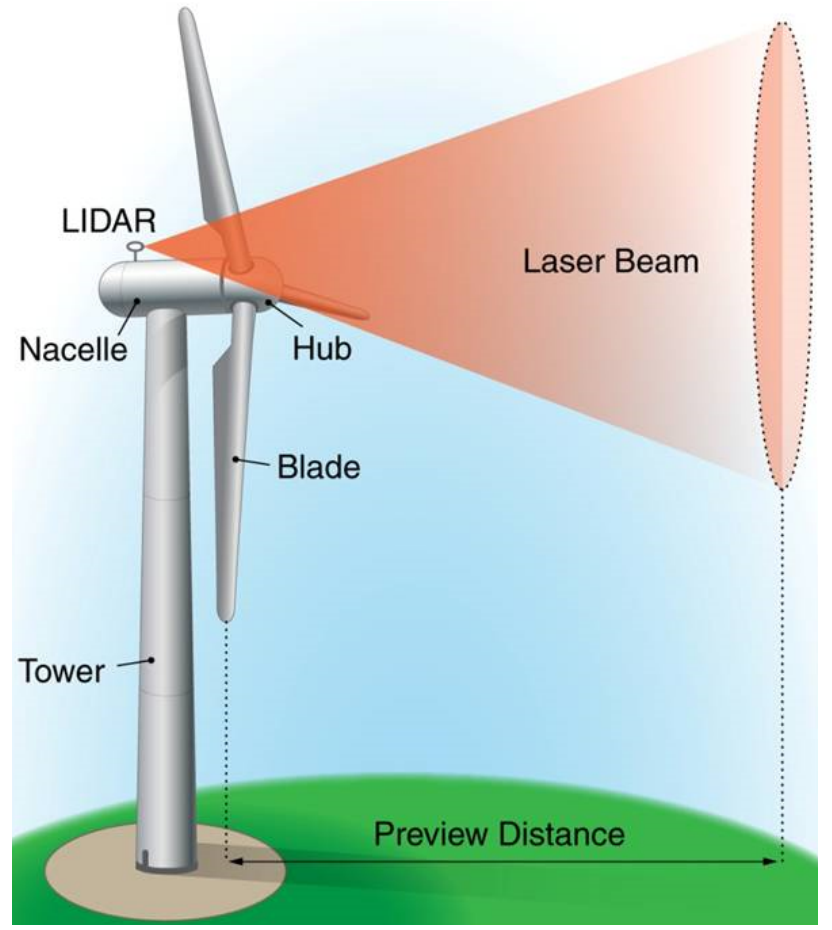

Fig. 4. Illustration showing a lidar mounted on top of the wind turbine nacelle showing a circular scanning pattern from a continuous-wave lidar. (Illustration by Al Hicks, NREL)

FAST simulation setup, improved results were found, where blade flap and tower fore-aft damage equivalent loads (DELs) were reduced using feedforward-feedback control over using a baseline feedback-only controller. Additionally, this came at no loss in power production [22].

In another study [23], simulations were performed to assess the effectiveness of using blade pitch control with wind preview measurements. The simulations in [23] assumed no wind evolution between the lidar measurement and wind turbine. Two types of controllers were designed in [23], a model-based controller with preview wind measurements, and a nonmodel-based preview controller. Simulation results showed that blade flap loads could be reduced by using the rotating preview measurements, as long as the measurements correlated well with what each blade experienced. If there was an error between the wind preview measurement and the wind that impacted the blade, then the feedforward controller would perform worse than the feedback-only controller [23]. It was noted in the analysis of [23] that when simulating lidars, wind evolution should be taken into account for the simulations to be more realistic and to better design a feedforward controller.

Another study [24] compared two independently developed feedforward controllers from [25] and [26], as well as two different lidar configurations, one a rotating continuouswave lidar, and the other a pulsed lidar. Although the feedforward pitch controllers were developed using very different methods, the simulation results showed similar performance for the two controllers in terms of load alleviation [24]. It was noted in [24] that the controller from [26] was simpler 
to design and more tunable, making it better for real-world applications. It was also noted in [24] that the pulsed lidar configuration is more realistic and provides more accurate wind speed estimates; however, the rotating continuous-wave lidar is capable of producing better blade effective wind speeds. The blade effective wind speed is an estimate of the wind that flows around the blade in order to produce torque for the generator. A later study [27] looked to extend the control techniques used in [25], using a $H_{\infty}$ control design for a floating offshore wind turbine. With the use of lidar, simulation results showed that a $H_{\infty}$ feedforwardfeedback controller was able to reduce the standard deviation of the rated generator speed by $44 \%$ and load mitigation was observed as well [27]. Later, a study [7] used the Bladed turbine simulator, rather than the FAST turbine simulator that was used in [23], [22], [24]. Despite the different turbine simulator, controller performance results were similar and showed a reduction in the blade root flap moment by $6 \%$ $12 \%$, and a reduced tower base fore-aft moment by $16 \%$ $20 \%$.

All of the work discussed so far in this subsection has been analysis by simulation alone; however, field test results have been achieved as well. In [19] a scanning pulsed lidar was installed on the nacelle of a wind turbine, and the lidar data were integrated into the turbine's supervisory control and data acquisition (SCADA) system in real time. This allowed the lidar's LOS measurements to be directly fed to the controller. The controller was designed to use the lidar preview measurement to allow for combined feedforwardfeedback control by applying a feedforward pitch rate update to the standard feedback controller. Additionally, Taylor's frozen turbulence hypothesis was assumed to determine the time delay between the lidar measurement and when the wind impacted the turbine. A similar method was used in [28]; however, a different turbine was used as well as different pulsed lidar with three fixed beams. Results from both [19] and [28] showed that improved rotor speed regulation was achieved by using the lidar-based feedforward controller. Later, a followup to these studies was done [29] and looked to improve the online data processing of the lidar measurement to correlate better with the rotor-effective wind speed using some of the techniques described in Section III-A. Field tests were done using a continuous-wave lidar in [29] and results showed that the online correlation did improve between the lidar measurement and the rotoreffective wind speed, which could be used to improve a lidarbased feedforward controller [29].

To summarize lidar-enhanced pitch control, it was found early on that it is important to include wind evolution in a lidar model when running simulations [23]. An additional study compared two controllers, one using a pulsed lidar, and the other using continuous-wave lidar, and found that both lidar configurations were capable of reducing turbine loads [24]. Improvements to lidar-turbine simulation environments and controller design led to load reductions in the blade flap root bending moment, and the tower base fore-aft bending moment with no change in the energy

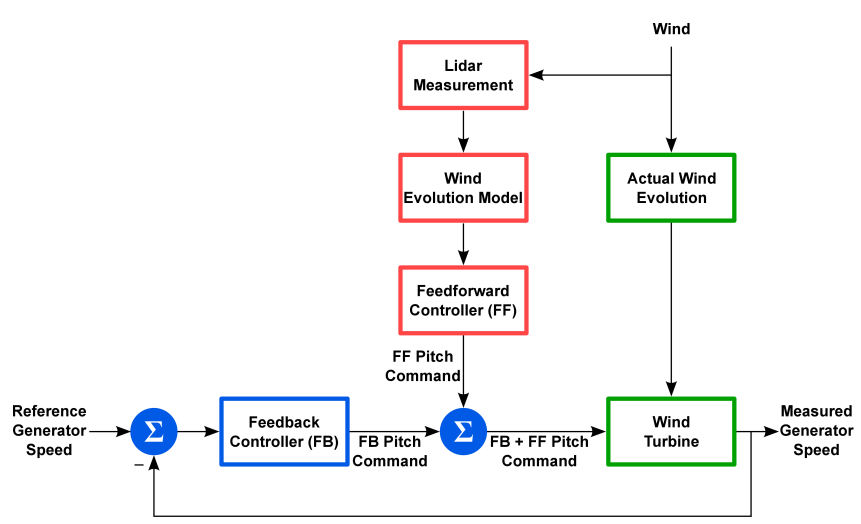

Fig. 5. An example of a lidar-based feedforward controller. The red blocks are additional control blocks for feedforward control added to the conventional feedback controller.

production [7], [27], [22], [26]. Lastly, field tests were also conducted that showed improved rotor speed regulation is achievable using lidar-based feedforward pitch control [19], [28], [29].

\section{Torque Control}

Similar to pitch control, a lidar could be used to provide preview wind speed information to the torque control aspect of the wind turbine controller when the turbine is operating in Region 2. Using the preview information, a controller can better track the optimal tip speed ratio of the wind turbine, which in turn will improve the aerodynamic efficiency of the rotor. In Fig. 5, changing the pitch command to a torque command in the block diagram would show a similar process for feedforward torque control.

In [30], an aeroelastic simulator was used to evaluate a controller with a lidar as an input for optimal torque tracking. Results from [30] showed that by using the optimal torque tracking controller, an improvement of $0.09 \%$ in power production could be achieved; however, this came at a cost of increasing the DEL of the rotor speed shaft by $8.9 \%$. The conclusion from [30] was that the power performance gains were marginal, and were not cost-effective when considering the increase in turbine loads. Similarly, in [7], a different turbine simulation model was used and saw a $0.2 \%$ increase in power production at the expense of unacceptable torque loads in the drivetrain. Additionally, in [31], a disturbance-tracking controller and an optimally tracking rotor controller, both augmented using lidar as well as a lidar-based preview controller, were developed and tested in simulation. Results from the three controllers in [31] showed that power performance was improved by less than $0.5 \%$ with an increase in the rotor shaft torque DEL by at least $5.7 \%$.

The work in [30] was extended in [32] to better account for the wind evolution between the lidar measurement and the rotor-effective wind speed. In [32], field test data were gathered and used as wind field inputs for aeroelastic simulations. In the simulations, an improvement in the optimal torque tracking was observed when using the lidar in Region 
2 , which was calculated to have a $0.3 \%$ power production increase; however, this was again at the expense of the rotor shaft DEL approximately doubling.

Another torque controller was developed in [33], with special consideration given to the Region 2.5 portion of the torque controller, where the generator speed reached its rated value but the generator torque has not. In [33], a disturbanceaccommodating control technique was used in combination with a continuous-wave lidar feedforward input to develop the controller. Simulation results showed that rotor speed regulation could be improved in Region 2.5, which showed promise for rotor shaft torque load mitigation. Although no power performance change was observed in these results, the improved rotor speed regulation without much cost in turbine loads was an improvement from other research discussed in this section on lidar feedforward torque control. In all, the research with feedforward torque control was not as promising as pitch control for improved performance.

\section{Yaw Control}

As mentioned earlier, it is the goal of a yaw controller to minimize yaw misalignment in order to maximize power production. For an upwind turbine, the yaw system can have a potential bias in the measurement because the vane is located in the near wake of the rotor, leading to a steady state yaw misalignment offset that the controller will not be able to account for. With a nacelle-mounted lidar, a wind direction measurement can be made ahead of the turbine and averaged over multiple points, reducing any biases in the wind direction measurement.

In [7], it was discussed that lidars could be used to improve yaw control of wind turbines; however, the simulations in the study were too short to draw any definitive conclusions. Additionally, in [30], field test data were gathered using a nacelle-mounted lidar on a wind turbine. Analysis comparing the lidar-measured wind direction to the wind turbine yaw direction showed that a yaw misalignment of $0.7^{\circ}$ was found, leading to a power loss of about $0.02 \%$ based on equations 6 and 7. Since then, a field test experiment showed that a nacelle-mounted lidar could be used to calibrate the conventional wind vane measurement system and correct any bias in the measurement [34]. A 2.4\% increase in the annual energy production was found in this study by using the lidar to correct for a bias [34]. The amount of increase can vary from turbine to turbine, as it depends on how much of a bias there is in the system to begin with. Additionally, another study showed that a lidar can be directly used to control the yaw set point of a wind turbine instead of using the lidar to calibrate the wind vane [35]. This study also showed similar results to [34], in that power improvement can be obtained when a bias exists in the conventional wind vane measurement system. The advantage to the method in [34] is that the lidar only needs to be installed on the turbine until the calibration is determined. It can then be moved to the next turbine. The advantage to the method in [35] is that it removes the nacelle wind vane from the control system, eliminating the need to perform periodic calibrations.

\section{E. Combined Controllers}

A combined controller for a wind turbine uses a combination of the techniques described in Section III-B, Section III$\mathrm{C}$ or Section III-D to develop a further optimal controller that balances the often-competing objectives of maximizing energy production and minimizing turbine loads. In [36], a nonlinear model-predictive controller (NMPC) was developed to use lidar measurements with predictions of the turbine state trajectories. Using the combined NMPC technique, simulation results from [36] showed reductions in turbine loads, and an increase in energy production. Another controller was developed using a flatness-based controller with lidar preview measurements to control both torque in Region 2 and pitch in Region 3 [37]. Using this approach, comparisons were made to a conventional feedback controller and a simple feedback-feedforward controller. The flatness-based controller showed improvements over both of the other controllers, with reductions in turbine loading, reductions in control actuation, and an increase in power production [37]. These results are promising as both load reduction and power increase are observed, whereas other studies usually show a trade-off between the two. The drawback to these controllers is that the models are computationally expensive and were not able to run in real time; however, this could be overcome in an industrial application by using hardware with adequate computational power.

In [38], a Region 3 combined feedback-feedforward controller was extended with a Region 2.5 combined feedbackfeedforward controller using a linear-quadratic-based preview collective pitch control scheme. Turbulent wind simulation studies showed that by including feedforward control in Region 2.5 , energy production could be improved by $3 \%$, while the feedforward Region 3 portion of the controller was able to reduce the tower base fore-aft loading by more than $10 \%$ without diminishing power production or reducing the rotor speed regulation [38]. Yet, the pitch actuator usage was increased [38]. This controller shows promise that both load reduction and increased energy production are possible when different regions of the controller are combined with feedforward controls.

\section{F. Lidar applications for wind farm control}

Recently, some research has focused on controls that improve the global performance of a wind farm, by coordinating the controls of individual turbines. Because neighboring wind turbines can impact each other through their wakes, there is potential for improved power output and reduced loading by trying to steer the wake propagation.

Many initial studies have been based on simulation and use "open-loop" control strategies that seek to determine the general controllability of wakes (see for example [39], [40], [41]). Studies such as these and more recent results from field testing and wind-tunnel tests have indicated promise for this approach [42] using indvidual pitch control and to a greater extent using yaw control.

However, when considering the complexity of controlling wakes within a wind farm, the applicability of lidars to 
the problem becomes apparent. Lidars provide a means for making measurements of the flow and estimating the wake locations for use in feedback [43]. Additionally, for wind farm control systems that use the yaw control system to steer wakes, a strong dependence is placed on accurately applying a particular misalignment between the turbine rotor and incoming wind mean flow direction. As shown in the work improving turbine yaw alignment error [34], [35], lidars can be very effective in providing an accurate measurement of wind turbine yaw alignment with the wind direction.

\section{ONGOING WORK}

In Section III-B, many papers were discussed in which feedforward pitch was used to reduce turbine loads in simulation. Additionally, two papers ([19], [28]) in that section also discussed feedforward pitch control field test results; however, the results were limited to improved rotor speed regulation in above rated winds. Field test work has been ongoing to extend this to reduce loads as predicted by the simulation studies. This is done by retuning the feedbackfeedforward gains such that the feedback portion of the controller is used to control the loads of the wind turbine, and the feedforward portion of the controller is used to control the rotor speed in Region 3. Initial results [44] have shown that by retuning the feedback-feedforward controller, the rotor speed regulation is as good as, if not better than the standard feedback controller, and that the tower fore-aft DEL can be reduced as well in Region 3.

Additionally, as mentioned in Section III-E, the NMPC controller described in [36] was very computationally expensive and not able to run in real time. Since then, ongoing work has been done to work through the computational hardware problem by separating the lidar, feedforward data processing, and turbine controller to each be handled by its own dedicated computer. This way, the NMPC could run its own separate process receiving inputs from the lidar and the turbine controller, and determining feedforward updates to send to the turbine controller to be applied to the wind turbine [45].

\section{CONCLUSIONS AND FUTURE WORK}

In this paper, a review of the use of lidars for enhanced wind turbine controls has shown that they can offer much improvement to lower the cost of energy of wind turbines with the potential for reducing wind turbine loads, and increasing energy production. Each of the three conventional control actuation methods (pitch, torque, and yaw) was investigated to show how lidars can be used with each actuator.

Many simulation studies have shown that feedforward pitch control can reduce the blade root flap bending moment, as well as the tower base fore-aft bending moment. Additional field tests have been performed to show that improved rotor speed regulation is achievable with lidar feedforward pitch control. Feedforward torque control strategies have also been investigated, and have shown that drivetrain loads increased drastically with little to no power increase. These studies showed that feedforward torque control has not been as promising as feedforward pitch control; however, ongoing research using a combined feedforward torque/pitch nonlinear model predictive controller shows promise for both reducing turbine loads as well as increasing power production. Yaw control was also discussed, and several studies found from field test data that power production could be increased either by using lidars as a means to precisely calibrate a nacelle-mounted wind vane, or by using a lidar to directly control the yaw position of the turbine.

Beyond the individual wind turbine, research was also discussed on using lidars at the wind plant level. Research at the wind plant level is largely just emerging, and most control studies have been done in simulation using "openloop" control methods to evaluate the general controllability of wakes. A first use of lidars for this research will be to extend the simulation studies of wake control to field test experiments. With this, a rear-facing nacelle-mounted lidar will be able to track a wind turbine's wake and verify the wind turbine's capability of controlling the wake. Additionally, as this research advances lidars will become very useful, if not necessary, to provide detailed real-time measurements of wakes within a wind farm as well as precisely controlling the yaw position of each wind turbine. With this, lidars can be used as additional wind-plant-level sensors for closedloop wind plant control, and further reductions in the LCOE for wind energy could be achieved.

\section{ACKNOWLEDGMENT}

This work was supported by the U.S. Department of Energy under Contract No. DE-AC36-08GO28308 with the National Renewable Energy Laboratory. Funding for the work was provided by the DOE Office of Energy Efficiency and Renewable Energy, Wind and Water Power Technologies Office.

\section{REFERENCES}

[1] E. Muljadi and C. Butterfield, "Pitch-controlled variable-speed wind turbine generation," Industry Applications, IEEE Transactions on, vol. 37, no. 1, pp. 240-246, Jan 2001.

[2] M. Harris, M. Hand, and A. Wright, "Lidar for turbine control," National Renewable Energy Laboratory, Golden, CO, Report No. NREL/TP-500-39154, 2006.

[3] L. Y. Pao and K. Johnson, "A tutorial on the dynamics and control of wind turbines and wind farms," in American Control Conference, 2009. ACC '09., St. Louis, Missouri, USA, June 2009, pp. 2076-2089.

[4] K. A. Kragh, P. A. Fleming, and A. K. Scholbrock, "Increased power capture by rotor speed-dependent yaw control of wind turbines," Journal of Solar Energy Engineering, vol. 135, no. 3, 2013.

[5] T. Mikkelsen, "Lidar-based research and innovation at DTU Wind Energy - a review," Journal of Physics: Conference Series, vol. 524, no. 1, 2014.

[6] S. Davoust, A. Jehu, M. Bouillet, M. Bardon, B. Vercherin, A. Scholbrock, P. Fleming, and A. Wright, "Assessment and optimization of lidar measurement availability for wind turbine control," in Proc. EWEA 2014, Barcelona, Spain, March 2014.

[7] E. A. Bossanyi, A. Kumar, and O. Hugues-Salas, "Wind turbine control applications of turbine-mounted lidar," Journal of Physics: Conference Series, vol. 555, no. 1, 2014.

[8] E. Simley, L. Y. Pao, R. Frehlich, B. Jonkman, and N. Kelley, "Analysis of wind speed measurements using continuous wave lidar for wind turbine control," in Proc. 49th AIAA Aerospace Sciences Meeting including the New Horizons Forum and Aerospace Exposition, Orlando, Florida, USA, January 2011. 
[9] D. Schlipf, J. Mann, and P. W. Cheng, "Model of the correlation between lidar systems and wind turbines for lidar assisted control," Journal of Atmospheric and Oceanic Technology, vol. 30, no. 10, pp. 2233-2240, 2013.

[10] E. Simley and L. Y. Pao, "Correlation between rotating lidar measurements and blade effective wind speed," in Proc. 51st AIAA Aerospace Sciences Meeting including the New Horizons Forum and Aerospace Exposition, Grapevine, Texas, USA, January 2013.

[11] D. Schlipf, A. Rettenmeier, F. Haizmann, M. Hofsäß, M. Courtney, and P. W. Cheng, "Model based wind vector field reconstruction from lidar data," in Proceedings of the German Wind Energy Conference DEWEK, Bremen, Germany, 2012.

[12] P. Towers and B. L. Jones, "Real-time wind field reconstruction from lidar measurements using a dynamic wind model and state estimation," Wind Energy, published online, 2014.

[13] S. Raach, D. Schlipf, F. Haizmann, and P. W. Cheng, "Three dimensional dynamic model based wind field reconstruction from lidar data," Journal of Physics: Conference Series, vol. 524, no. 1, 2014.

[14] F. Dunne and L. Y. Pao, "Benefit of wind turbine preview control as a function of measurement coherence and preview time," in American Control Conference (ACC), 2013, Washington, D.C., USA, June 2013, pp. 647-652

[15] G. I. Taylor, "The spectrum of turbulence," Proceedings of the Royal Society of London A: Mathematical, Physical and Engineering Sciences, vol. 164, no. 919, pp. 476-490, 1938 .

[16] D. Schlipf, D. Trabucchi, O. Bischoff, M. Hofsäß, J. Mann, T. Mikkelsen, A. Rettenmeier, J. Trujillo, and M. Kühn, Testing of Frozen Turbulence Hypothesis for Wind Turbine Applications with a Scanning LIDAR System. ISARS, 2010.

[17] E. A. Bossanyi, "Un-freezing the turbulence: improved wind field modelling for investigating lidar-assisted wind turbine control," in Proc. EWEA Annual conference, Copenhagen, Denmark, 2012.

[18] F. Dunne, L. Y. Pao, D. Schlipf, and A. K. Scholbrock, "Importance of lidar measurement timing accuracy for wind turbine control," in Proc. American Controls Conference, Portland, Oregon, USA, June 2014, pp. 3716-3721.

[19] D. Schlipf, P. Fleming, F. Haizmann, A. Scholbrock, M. Hofsäß, A. Wright, and P. W. Cheng, "Field testing of feedforward collective pitch control on the CART2 using a nacelle-based lidar scanner," Journal of Physics: Conference Series, vol. 555, no. 1, 2012.

[20] E. Simley and L. Y. Pao, "A longitudinal spatial coherence model for wind evolution based on large-eddy simulation," in American Control Conference (ACC), 2015, Chicago, Illinois, USA, July 2015, pp. 37083714.

[21] D. Schlipf and M. Kühn, "Prospects of a collective pitch control by means of predictive disturbance compensation assisted by wind speed measurements," in Proceedings of the 9th German Wind Energy Conference DEWEK, Bremen, Germany, November 2008.

[22] F. Dunne, L. Y. Pao, A. D. Wright, B. Jonkman, and N. Kelley, "Adding feedforward blade pitch control to standard feedback controllers for load mitigation in wind turbines," Mechatronics, vol. 21, no. 4, pp. $682-690,2011$.

[23] J. Laks, L. Y. Pao, A. Wright, N. Kelley, and B. Jonkman, "Blade pitch control with preview wind measurements," in Proc. AIAA Aerospace Sciences Meeting, Orlando, Florida, USA, January 2010.

[24] F. Dunne, D. Schlipf, L. Y. Pao, A. D. Wright, B. Jonkman, N. Kelley, and E. Simley, "Comparison of two independent lidar-based pitch control designs," in Proc. AIAA Aerospace Sciences Meeting, Nashville, Tennessee, USA, January 2012.

[25] F. Dunne, L. Y. Pao, A. D. Wright, B. Jonkman, and N. Kelley, "Combining standard feedback controllers with feedforward blade pitch control for load mitigation in wind turbines," in Proc. AIAA Aerospace Sciences Meeting, Orlando, Florida, USA, January 2010.

[26] D. Schlipf, S. Schuler, P. Grau, F. Allgöwer, and M. Kühn, "Lookahead cyclic pitch control using lidar," in Proc. The Science of Making Torque from Wind, Heraklion, Greece, June 2010.

[27] S. T. Navalkar, J. W. van Wingerden, P. A. Fleming, and G. A. M. van Kuik, "Integrating robust lidar-based feedforward with feedback control to enhance speed regulation of floating wind turbines," in American Control Conference (ACC), 2015, Chicago, Illinois, USA, July 2015 , pp. 3070-3075.

[28] A. Scholbrock, P. Fleming, L. Fingersh, A. Wright, D. Schlipf, F. Haizmann, and F. Belen, "Field testing LIDAR-based feed-forward controls on the NREL controls advanced research turbine," in Proc. 51st AIAA Aerospace Sciences Meeting including the New Horizons Forum and Aerospace Exposition, Grapevine, Texas, USA, January 2013.

[29] F. Haizmann, D. Schlipf, S. Raach, A. Scholbrock, A. Wright, C. Slinger, J. Medley, M. Harris, E. Bossanyi, and P. W. Cheng, "Optimization of a feed-forward controller using a CW-lidar system on the CART3," in American Control Conference (ACC), 2015, Chicago, Illinois, USA, July 2015, pp. 3715-3720.

[30] D. schlipf, S. Kapp, J. Anger, O. Bischoff, M. Hofsäß, A. Rettenmeier, and M. Kühn, "Prospects of optimization of energy production by lidar assisted control of wind turbines," in EWEA 2011 conference proceedings, Brussels, Belgium, 2011.

[31] N. Wang, K. Johnson, and A. Wright, "Comparison of strategies for enhancing energy capture and reducing loads using lidar and feedforward control," Control Systems Technology, IEEE Transactions on, vol. 21, no. 4, pp. 1129-1142, July 2013.

[32] D. Schlipf, P. Fleming, S. Kapp, A. Scholbrock, F. Haizmann, F. Belen, A. Wright, and P. W. Cheng, "Direct speed control using lidar and turbine data," in American Control Conference (ACC), 2013, Washington, D. C., USA, June 2013.

[33] N. Wang, K. Johnson, A. Wright, and C. Carcangiu, "Lidar-assisted wind turbine feedforward torque controller design below rated," in American Control Conference (ACC), 2014, Portland, Oregon, USA, June 2014, pp. 3728-3733.

[34] P. A. Fleming, A. K. Scholbrock, A. Jehu, S. Davoust, E. Osler, A. D. Wright, and A. Clifton, "Field-test results using a nacelle-mounted lidar for improving wind turbine power capture by reducing yaw misalignment," Journal of Physics: Conference Series, vol. 524, no. 1 , 2014.

[35] A. Scholbrock, P. Fleming, A. Wright, C. Slinger, J. Medley, and M. Harris, "Field test results from lidar measured yaw control for improved yaw alignment with the NREL Controls Advanced Research Turbine," in Proc. 33rd Wind Energy Symposium AIAA SciTech Conference, Kissimmee, Florida, USA, January 2013.

[36] D. Schlipf, D. J. Schlipf, and M. Kühn, "Nonlinear model predictive control of wind turbines using lidar," Wind Energy, vol. 16, no. 7, pp. $1107-1129,2013$

[37] D. Schlipf and P. W. Cheng, "Flatness-based feedforward control of wind turbines using lidar," in Proceedings of the 19th World Congress of the International Federation of Automatic Control, Cape Town, South Africa, August 2014.

[38] N. Wang, K. Johnson, A. Wright, and C. Carcangiu, "LIDAR-assisted preview controllers design for a MW-scale commercial wind turbine model," in Decision and Control (CDC), 2013 IEEE 52nd Annual Conference on, Florence, Italy, December 2013, pp. 1678-1683.

[39] J. Wagenaar, L. Machielse, and J. Schepers, "Controlling wind in ECN's scaled wind farm," Proc. Europe Premier Wind Energy Event, pp. 685-694, 2012.

[40] P. A. Fleming, P. M. Gebraad, S. Lee, J.-W. van Wingerden, K. Johnson, M. Churchfield, J. Michalakes, P. Spalart, and P. Moriarty, "Evaluating techniques for redirecting turbine wakes using SOWFA," Renewable Energy, vol. 70, pp. 211-218, 2014.

[41] P. M. O. Gebraad, F. W. Teeuwisse, J. W. van Wingerden, P. A Fleming, S. D. Ruben, J. R. Marden, and L. Y. Pao, "A data-driven model for wind plant power optimization by yaw control," pp. 3128 3134, June 2014.

[42] B. D. Hirth, J. L. Schroeder, W. S. Gunter, and J. G. Guynes, "Investigating the impact of turbine control on turbine wakes using advanced doppler radar," in Windpower, 2014, p. 1550.

[43] S. Raach, D. Schlipf, J. J. Trujillo, and P. W. Cheng, "Model-based wake tracking using lidar measurements for wind farm control," in Large Wind-Power Plants: Interaction, Control and Integration, July 2015, p. 2015.

[44] A. A. Kumar, E. A. Bossayni, A. K. Scholbrock, P. A. Fleming, M. Boquet, and R. Krishnamurthy, "Field testing of lidar assisted feedforward control algorithms for improved speed control and fatigue load reduction on a $600 \mathrm{kw}$ wind turbine," in EWEA 2015 Conference Proceedings, Paris, France, November 2015.

[45] D. Schlipf, P. Fleming, S. Raach, A. Scholbrock, F. Haizmann, R. Krishnamurthy, M. Boquet, A. Wright, and P. W. Cheng, "An adaptive data processing technique for lidar-assisted control to bridge the gap between lidar systems and wind turbines," in EWEA 2015 Conference Proceedings, Paris, France, November 2015. 